\title{
Potencial da rama de mandioca para uso na alimentação de ruminantes: Revisão
}

\section{Talita Carvalho Pestana ${ }^{1} *$ \& Gustavo Henrique Frias Castro ${ }^{2}$}

${ }^{1}$ Discente do curso de Bacharelado em Zootecnia na Universidade Federal dos Vales do Jequitinhonha e Mucuri-Diamantina- Minas Gerais- Brasil

${ }^{2}$ Docente do curso de Bacharelado em Zootecnia na Universidade Federal dos Vales do Jequitinhonha e Mucuri- Diamantina- Minas Gerais- Brasil

*Autor para correspondência, E-mail: talitazootecnia@gmail.com

RESUMO. A alimentação representa o componente de maior custo na produção animal. A busca de alimentos alternativos que apresentem valor nutritivo adequado, boa disponibilidade e custo compatível com o sistema de produção, pode ser uma importante ferramenta para o incremento na produção animal. Nesse contexto destaca-se a cultura da mandioca (Manihot esculenta, Crantz) em função do bom valor nutricional, rusticidade, alta produtividade e grande difusão no país. Tradicionalmente cultivada em países de clima tropical, a mandioca tem suas raízes empregadas na alimentação humana e animal. Porém, a parte aérea (rama) caracterizada como resto cultural não é totalmente aproveitada, sendo que boa parte é perdida durante a colheita ou no processo de apara. Tal resíduo pode ser aproveitado como alimento protéico na alimentação de ruminantes na forma in natura, ensilada ou fenada. $O$ presente trabalho teve como objetivo revisar os aspectos gerais sobre a rama de mandioca e seu potencial de uso na alimentação de ruminantes.

Palavras chave: Alimentos, folhas, hastes, Maninhot esculenta, parte aérea

\section{Potential of cassava foliage for use in ruminant feed}

\begin{abstract}
The feed is the major cost component in animal production. The search for alternative foods that present adequate nutritional value, good availability and cost compatible with the production system can be an important tool for the increase in animal production. In this context there is the cassava (Manihot esculenta, Crantz) with of good nutritional value, hardiness, high yield and wide dissemination in the country. Traditionally grown in tropical countries, cassava has its roots employed in human and animal feeding. But the shoot (raw) characterized as cultural rest is lost during harvesting or trimming process, which allowed for incorporation into the soil. This residue can be availed as food protein in ruminants feeding in the form nature, made into hay or silage. This work was carried out to review the main aspects of cassava raw, their preparation and use in ruminant feeding.
\end{abstract}

Key words: Aerial parts, food, leaves, Maninhot esculenta, petioles, stems.

\section{Introdução}

A alimentação representa o componente de maior custo na produção animal. No atual cenário, as margens de retorno econômico das atividades pecuárias encontram-se cada vez mais restritas e a busca por maior eficiência produtiva torna-se uma questão de sobrevivência. Nesse aspecto $\mathrm{o}$ aproveitamento dos subprodutos provenientes da cultura da mandioca (Manihot esculenta, Crantz) ganha importância pelo expressivo valor econômico, face ao volume dos resíduos, sua disponibilidade e utilização na forma de insumos na alimentação de ruminantes.

No Brasil, o principal recurso forrageiro para ruminantes são as gramíneas tropicais, cuja produção e qualidade apresentam uma ampla flutuação ao longo do ano em virtude de fatores climáticos. A produção e a qualidade das forrageiras tropicais durante a época seca do ano estão entre os fatores responsáveis pela redução na produtividade dos animais em todo o Brasil. Cultivada em todo o território nacional, a mandioca, demonstra ter capacidade de 
adaptação a diferentes climas, solos e manejos. Porém, para cada região de cultivo, alguns parâmetros técnicos específicos devem ser levados em consideração para se obter maior produtividade e qualidade, tais como época de plantio, preparo de solo, escolha da variedade, seleção de ramas, população de plantas, espaçamento, controle de doenças e pragas, além do controle de planta daninhas.

As pesquisas com a mandioca e seus subprodutos têm aumentado nos últimos anos em decorrência da facilidade de cultivo, da adaptabilidade a diversos tipos de solo, da resistência a períodos de estiagem com expressiva produção, além da possibilidade de utilização da sua parte aérea como fonte de proteína de baixo custo (Carvalho, 1983, Ferreira et al., 2008). Na alimentação animal a parte aérea da mandioca pode ser usada como fonte de proteína nas formas in natura, desidratada ou fenada e ensilada. A possibilidade de oferta desta parte da planta está intimamente ligada ao manejo empregado para a produção de raízes.

A rama da mandioca apresenta elevada concentração de proteína bruta e reduzido teor de fibra quando comparado à maioria das forrageiras tropicais (Modesto et al., 2008). As folhas possuem entre 15 e $40 \%$ de proteína bruta na matéria seca, além de vitaminas e minerais, variando de acordo com a variedade, idade da planta e manejo da cultura (Modesti et al., 2007, Silva et al., 2009, Aletor, 2010).

Devido ao bom aporte de proteínas, minerais, aminoácidos e vitaminas, as folhas da mandioca podem ser utilizadas como suplemento alimentar para animais; embora, seu consumo direto deva ser limitado pela presença de agentes tóxicos e anti nutricionais, como o ácido cianídrico, fazendo necessário o tratamento deste subproduto para que haja redução destes compostos a níveis seguros (Fasuyi \& Aletor, 2005, Bohnenberger et al., 2010). Este trabalho tem por objetivo caracterizar a rama de mandioca e seu potencial de uso na alimentação de ruminantes.

\section{Características gerais da cultura da mandioca}

A mandioca (Manihot esculenta, Crantz), também conhecida como aipim e macaxeira, é planta originária da América do Sul, provavelmente da região Nordeste e Central do Brasil, onde já era cultivada pelos índios. Foi descrita pela primeira vez em 1573 por Magalhães Gandavo, sendo disseminada no mundo pela colonização européia no século XVIII.

Por ser adaptável a diversos tipos de clima e solo, a mandioca é cultivada em várias regiões do mundo. A Nigéria, o Brasil e a Tailândia são os países que dominam a produção mundial. A produção africana não tem caráter comercial; ao contrário, apresenta-se como de subsistência. No Brasil, segundo maior produtor, coexiste a produção de subsistência e a comercial, ambas destinadas ao mercado interno. Já na Tailândia a produção da mandioca tem caráter comercial e de exportação. A participação do Brasil no mercado internacional é praticamente desprezível. As exportações brasileiras, quando ocorrem, destinam-se aos países da América do Sul e, em menor proporção, aos Estados Unidos da América (Alves et al., 2003).

A cultura da mandioca tem papel importante na alimentação humana; é fonte geradora de emprego e de renda para agricultores familiares e consumidores de baixo poder aquisitivo, sobretudo nas regiões mais pobres do país (Conceição, 1987). No mundo, a mandioca é mais utilizada na alimentação humana, sendo que, em cerca de 14 países, ela é o alimento predominante na dieta diária, servindo de subsistência para aproximadamente 200 milhões de pessoas (Conceição, 1987). Possui, também, grande importância como matéria-prima para diversos segmentos da economia como as indústrias de alimentos, têxtil, papelaria, farmacêutica, alimentação animal, dentre outras.

A produção de mandioca é predominantemente realizada por agricultores familiares e camponeses. Segundo dados do Instituto Brasileiro de Geografia e Estatística (IBGE, 2013) 74,5\% do plantio são efetuados em áreas inferiores a 10 hectares. Desta forma, a integração entre as atividades pecuárias e a produção agrícola na propriedade garante redução dos custos do produtor, tornando o sistema sustentável.

De acordo com o IBGE (2013), a área de mandioca plantada no Brasil em 2012 foi de aproximadamente 1,8 milhões de hectares, com uma produção estimada de 25,7 milhões de toneladas de raízes, obtendo-se um rendimento de 13,75ton./ha. O Nordeste e o Norte foram responsáveis por $26 \%$ e $38 \%$ da produção nacional em 2012, com predomínio de sistemas familiares que utilizam baixa tecnologia. Já as regiões Sul, Sudeste e Centro-Oeste apresentaram 
respectivamente $22 \%, 8,6 \%$ e $5,6 \%$ da produção nacional, respectivamente, apresentando um caráter produtivo mais industrial (IBGE, 2013).

A mandioca pertence à família das Euphorbiaceae, sendo a Manihot esculenta espécie de maior interesse agronômico entre as 1.200 espécies existentes. As plantas são herbáceas quando novas, lenhosas, arbustivas ou subarbustivas na maturidade, com altura variando de 1 a 5 metros (Carvalho, 1983). Devido à sua adaptabilidade a diferentes ambientes ecológicos e seu potencial produtivo, a mandioca é cultivada em praticamente todos os estados brasileiros. Esse vegetal apresenta-se como uma ótima alternativa para alimentação animal devido a sua disponibilidade justamente no período seco do ano, de junho a outubro em que os pastos caem em quantidade e qualidade (Moreira et al., 2004).

A mandioca pode ser cultivada com ótima produtividade numa faixa que vai de $30^{\circ}$ na latitude norte a $30^{\circ}$ na latitude sul, e altitudes até 800 metros, onde ocorrem condições climáticas favoráveis para seu desenvolvimento. A temperatura ideal está entre $25^{\circ} \mathrm{C}$ e $29^{\circ} \mathrm{C}$, exigindo precipitações entre $1.000 \mathrm{~mm}$ e 1.500 $\mathrm{mm}$ anuais. Entretanto, apresenta resistência à seca, sendo cultivada em regiões semi áridas com $500 \mathrm{~mm}$ a $700 \mathrm{~mm}$ de chuvas por ano. Apresenta baixa exigência em fertilidade e desenvolve-se melhor em solos com textura franco-arenosa a argilo arenosa, com pH 6,5 (Machado et al, 2009).

Para fins práticos, a planta da mandioca pode ser dividida em parte aérea (hastes, pecíolos e folhas) e parte subterrânea (raízes tuberosas). A despeito das variações inerentes à variedade utilizada e às influências das condições de solo e ambiente da cultura, de modo geral, observam-se na planta madura aproximadamente $50 \%$ de raízes tuberosas, $40 \%$ de hastes, pecíolos e $10 \%$ de folhas.

Dentre outros fatores, a produtividade da mandioca depende das condições climáticas, da fertilidade do solo e da cultivar plantada, variando de 10 a 35 toneladas por hectare de raízes e 8 a 30 toneladas por hectare de parte aérea (Carvalho, 1983). A raiz de mandioca apresenta 60 a $65 \%$ de umidade; 21 a $33 \%$ de amido; 1,0 a $1,5 \%$ de proteína bruta; 0,18 a $0,24 \%$ de extrato etéreo; 0,70 a $1,06 \%$ de fibra bruta e 0,60 a $0,90 \%$ de matéria mineral (Modesto et al., 2004). Porém a composição é variável de acordo com as condições ambientais em que a planta se desenvolveu, com o cultivar utilizado e com a idade da planta.

A mandioca apresenta a peculiaridade de poder ser manejada com duplo propósito de produção de amido, principal componente das raízes tuberosas, e de proteína, presente em elevadas concentrações nas folhas. Sendo assim, sua utilização na alimentação de ruminantes apresenta vantagens, já que a raiz substitui alimentos energéticos de alto custo, utilizados tradicionalmente na dieta de monogástricos, além da parte aérea representa um suplemento protéico que pode ser utilizado durante todo o ano, reduzindo gastos com alimentos concentrados.

\section{Fatores anti nutricionais e tóxicos presentes na mandioca}

A defesa química é uma das formas de proteção das plantas contra os herbívoros; envolve a elaboração e acumulação de substâncias orgânicas que, uma vez ingeridas, inibem o consumo. Estas podem ter um sabor amargo, ser venenosas, ter um odor desagradável ou ainda ter efeitos anti nutricionais (Harborne, 1999). As toxinas são, em geral, metabolitos secundários das plantas, isto é, substâncias químicas que não estão diretamente envolvidas no metabolismo fundamental da mesma. A maioria não contribui para o ganho de energia ou integridade estrutural. São extremamente diversas, apresentando uma grande variedade de tipos químicos, derivando principalmente dos metabolismos dos acetatos ou de aminoácidos (Harborne, 1999). Por vezes, a substância tóxica para o animal não é o composto em si, mas os metabolitos resultantes da sua degradação.

Devido à relevância que os fatores tóxicos têm perante a alimentação de ruminantes, serão discutidos dentre eles os compostos cianogênicos. $\mathrm{O}$ processo denominado cianogênese é a capacidade da planta de produzir ácido cianídrico ou íon de cianeto $(\mathrm{HCN})$ sob circunstâncias particulares sendo observada em várias espécies vegetais.

A mandioca e demais espécies do gênero Manihot apresentam substâncias tóxicas que são liberados quando a planta sofre danos mecânicos e/ou fisiológicos. O processo de formação do ácido cianídrico ocorre em todas as espécies do gênero, inclusive nas variedades consideradas mansas (macaxeiras ou aipins). As variedades mais tóxicas diferem das menos tóxicas pela quantidade de cianetos na polpa das raízes 
(Carvalho, 1983). As classificadas como mansas são àquelas cujo teor de ácido cianídrico por quilo de raiz fresca não ultrapassa $50 \mathrm{mg}$. Já a mandioca brava, amarga ou venenosa, de uso industrial são aquelas cujo teor de ácido cianídrico por quilo de raiz fresca é superior a $100 \mathrm{mg}$. Para bovinos e ovinos, a dose letal é de cerca de $2 \mathrm{mg} / \mathrm{kg}$ de $\mathrm{HCN}$ de peso vivo, quando o animal ingere o glicosídeo puro e de $200 \mathrm{mg} / \mathrm{kg}$ de $\mathrm{HCN}$ se ingerido como forragem seca.

O ácido cianídrico é produzido após a ocorrência de danos no tecido da planta, seu processo de formação é dividido em duas fasese tem início com as principais substâncias cianogênicas: a linamarina e lotaustralina. Ambas assubstâncias (localizadas nos vacúolos) na presença de água, entram em contato com a enzima linamarase (localizada na parede celular) ocorrendo à hidrólise das mesmas. A degradação das substâncias cianogênicas produz glicose e acetona cianídrica e na segunda fase, a enzima hidroxinitriloliase catalisa a degradação da acetona cianídrica para produção de acetona e ácido cianídrico $(\mathrm{HCN})$ conforme mostra o esquema abaixo:

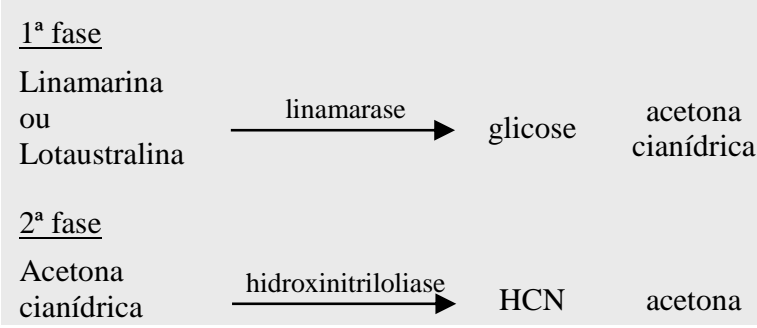

A enzima dessa segunda fase, também se encontra na parede celular e a reação pode ocorrer espontaneamente, quando o $\mathrm{pH}$ é superior a quatro e a temperatura superior a $30^{\circ} \mathrm{C}$.

A utilização das raízes e da parte aérea da mandioca na alimentação de animais deve ser fornecida com cautela devido ao $\mathrm{HCN}$, que ao ser ingerido em grandes quantidades provoca envenenamento e frequentemente mortes, e em doses reduzidas provocam diminuição da produtividade; transtornos gastrintestinais ou diminuição do crescimento. Porém, no processo de secagem, os compostos tóxicos, são eliminados, podendo as folhas e raízes, serem empregadas na alimentação humana e animal.

Segundo Kass et al. (1981) o ácido cianídrico pode ser facilmente volatilizado quando as folhas são submetidas ao sol e ao calor. Estes autores estudaram três métodos de eliminação do ácido cianídrico em folhas de mandioca. Para eliminação de $71 \%$ de ácido cianídrico gastou-se 108 horas de secagem à sombra, 72 horas de secagem ao sol e 48 horas de secagem em estufa, com circulação de ar a $60^{\circ} \mathrm{C}$. Com relação à secagem com ar quente, Maner (1972) salienta que realmente ela é rápida e eficiente na eliminação do ácido cianídrico livre; porém deixa grande parte do glicosídeo cianogênico linamarina intacto. Este fato pode se constituir em grave problema na alimentação animal porque o ácido clorídrico no estômago hidrolisa os glicosídeos cianogênicos liberando o $\mathrm{HCN}$. Contudo, a secagem ao sol possibilita a ação da enzima linamarase, eliminando tanto o ácido cianídrico livre como os glicosídeos, apresentando a vantagem de ser um método simples.

\section{Parte aérea da mandioca}

Apesar de apresentar excelente qualidade nutricional e aceitabilidade pelos animais, seu aproveitamento como fonte de proteína de baixo custo para produção tem sido reduzido. Isso é atribuído, principalmente, à falta de conhecimento dos produtores e técnicos acerca dos critérios para sua utilização (Carvalho, 1983).

A parte aérea da mandioca, ou rama, compreende a porção da planta que fica acima do solo considerada um resíduo gerado na colheita das raízes. É constituída por ramos, pecíolos e folhas em proporções variáveis. Sua composição bromatológica varia de acordo com a proporção entre hastes e folhas, variedade utilizada, época de colheita, manejo adotado, fertilidade do solo e condições climáticas. Silva et al. (2009) trabalhando com a parte aérea da mandioca aos 14 meses de idade, encontrou diferenças na composição das hastes $(47 \%$ da parte aérea total),pecíolos (25\%) e folhas (28\%), conforme mostrado na Tabela 1.

Tabela 1. Composição químico bromatológica da rama de mandioca aos 14 meses de idade

\begin{tabular}{llll}
\hline \multirow{2}{*}{ Parâmetros } & \multicolumn{3}{c}{ Parte aérea } \\
\cline { 2 - 4 } & Haste & Pecíolo & Folha \\
\hline Proteína bruta, \% & 4,32 & 8,41 & 27,49 \\
Extrato Etéreo, \% & 0,91 & 1,59 & 6,7 \\
Fibra det. neutro, \% & 63,62 & 50,52 & 32,98 \\
Açúcar solúvel, \% & 20,13 & 17,48 & 11,3 \\
Cinzas, \% & 0,03 & 0,06 & 0,09 \\
\hline
\end{tabular}

Fonte: Silva et al. (2009). 
Segundo Machado et al. (2009), uma folhagem de mandioca de boa qualidade deve apresentar, com base na matéria seca, 18,0 a $22,0 \%$ de proteína bruta $(\mathrm{PB}), 15,0$ a $20,0 \%$ de fibra bruta (FB), 4,0 a 6,0\% de extrato etéreo (EE), 8,0 a $12,0 \%$ de cinzas e 40,0 a $50,0 \%$ de extrativo não nitrogenado (ENN). As folhas apresentam nível relativamente alto de $\mathrm{EE}(5,0$ a $7,0 \%$ da MS), com quantidades relevantes de ácidos graxos essenciais, xantofilas e pigmentos (Machado et al., 2009). Em um estudo elaborado por Carvalho (1983) avaliou o terço superior por completo e apresentou $25 \%$ de MS, $16 \%$ de PB, $14,5 \%$ de $\mathrm{FB}, 7,5 \%$ de $\mathrm{EE}$ e $12,0 \%$ de matéria mineral (MM). Avaliando a folha da mandioca fresca
Gómez \& Valdivieso (1985) observaram que a quantidade de proteína encontrada variou de 17\% a $34 \%$ e que na parte aérea (folha + ramos) variou de $13 \%$ a $20 \%$.

Ravindran (1992) avaliou e comparou as folhas de mandioca utilizadas para alimentação animal com a alfafa (Tabela 2). Este autor observou maiores valores de PB e EE nas folhas de mandioca, e também constatou que esta possui um bom aporte de minerais, sendo ricas em $\mathrm{Ca}$, $\mathrm{Fe}, \mathrm{Mg}, \mathrm{Mn}$ e $\mathrm{Zn}$.Em relação à qualidade da proteína da folha, o autor verificou um ótimo aporte de aminoácidos com elevadas concentrações de lisina conforme ilustrado na Tabela 2.

Tabela 2. Valores médios da composição químico bromatológica, perfil de aminoácidos essenciais e conteúdo mineral da folha de mandioca e alfafa

\begin{tabular}{|c|c|c|}
\hline Parâmetros & Folha de Mandioca & Alfafa \\
\hline Proteína Bruta \% & $21,0^{c}(16,7-39,9)^{b}$ & $20,0^{\mathrm{a}}$ \\
\hline Extrato Etéreo \% & $5,5^{c}(3,8-10,5)^{\mathrm{b}}$ & $3,5^{\mathrm{a}}$ \\
\hline Fibra Bruta \% & $20,0^{c}(4,8-29,0)^{\mathrm{b}}$ & $20,0^{\mathrm{a}}$ \\
\hline Cinzas $\%$ & $8,5^{c}(1,56-1,94)^{\mathrm{b}}$ & $10,5^{\mathrm{a}}$ \\
\hline Arginina $\%$ PB & $5,3^{a}(4.0-5.7)^{b}$ & $4,9^{e}$ \\
\hline Lisina \% PB & $5,9^{a}(3.8-7.5)^{b}$ & $4,4^{e}$ \\
\hline Metionina \% PB & $1,9^{a}(1.3-2.0)^{b}$ & $1,7^{e}$ \\
\hline Cistina\% PB & $1,4^{a}(0.7-1.4)^{b}$ & $1,2^{e}$ \\
\hline AA sulfurados $\%$ PB & $3,3^{a}(2.0-3.3)^{b}$ & $2,9^{e}$ \\
\hline Triptofano \% PB & $2,0^{a}$ & $2,3^{e}$ \\
\hline Histidina \% PB & $2,3^{a}(1.1-2.5)^{b}$ & $2,1^{e}$ \\
\hline Isoleucina \% PB & $4,5^{a}(3.9-5.0)^{b}$ & $4,9^{e}$ \\
\hline Leucina \% PB & $8,2^{a}(7.2-8.9)^{b}$ & $7,5^{e}$ \\
\hline Fenilalanina \% PB & $5,4^{a}(5.3-5.4)^{b}$ & $5,2^{e}$ \\
\hline Treonina \% PB & $4,4^{a}(3.2-5.0)^{b}$ & $4,4^{e}$ \\
\hline Valina \% PB & $5,6^{a}(5.1-5.7)^{b}$ & $6,0^{e}$ \\
\hline $\mathrm{K} \%$ & $1,28^{\mathrm{c}}$ & $2,50^{\mathrm{a}}$ \\
\hline $\mathrm{Ca} \%$ & $1,45^{\mathrm{c}}$ & $1,50^{\mathrm{a}}$ \\
\hline $\mathrm{Mg} \%$ & $0,42^{\mathrm{c}}$ & $0,32^{\mathrm{a}}$ \\
\hline $\mathrm{P} \%$ & $0,45^{\mathrm{c}}$ & $0,25^{\mathrm{a}}$ \\
\hline $\mathrm{Na} \%$ & $0,02^{\mathrm{c}}$ & $0,08^{\mathrm{a}}$ \\
\hline $\mathrm{Zmg} / \mathrm{Kg}$ & $149^{\mathrm{c}}$ & $19^{a}$ \\
\hline $\mathrm{Mnmg} / \mathrm{Kg}$ & $52^{c}$ & $34^{a}$ \\
\hline Femg/Kg & $259^{\mathrm{c}}$ & $281^{a}$ \\
\hline $\mathrm{Cu} \mathrm{mg} / \mathrm{Kg}$ & $12^{\mathrm{c}}$ & $9^{a}$ \\
\hline
\end{tabular}

${ }^{\mathrm{a}}$ Allen (1994); ${ }^{\mathrm{b}}$ Valores entre parênteses referem-se a intervalos descritos na literatura; ${ }^{\mathrm{c}}$ Ravindran \& Ravindran (1988); ${ }^{\mathrm{e} E g g u m}(1970)$.

Fonte: Ravindran (1992). 
A composição em aminoácidos é de grande importância do ponto de visto nutricional e funcional. Entre os resultados existem variações, mas todos os autores mostram que, com exceção da metionina, a composição em aminoácidos essenciais da rama é satisfatória. De fato, outros trabalhos realizados com diferentes variedades de mandioca cultivadas sobre as mesmas condições, mostraram que as diferenças na composição em aminoácidos são insignificantes, conforme apresentados na tabela 3 (Otoul, 1973 Citado por (Guerroué et al., 1996).

Tabela 3. Composição em aminoácidos das folhas de mandioca e concentrado protéico da folha (CPF).

\begin{tabular}{lcccc}
\hline $\begin{array}{l}\text { Aminoácidos } \\
(\% \text { PB })\end{array}$ & $\mathrm{a}$ & Folhas de Mandioca & & CPF da \\
\hline Alanina & 5,71 & $\mathrm{~b}$ & $\mathrm{c}$ & Mandioca \\
Arginina & 5,5 & 5,98 & 6,19 & 6,72 \\
Aspártico & 9,57 & 5,28 & 6,12 & 6,53 \\
Cisteína & 1,29 & 10,14 & 9,63 & 10,8 \\
Fenilalanina & 5,89 & 1,37 & 1,04 & 0,49 \\
Glicina & 5,2 & 5,82 & 5,53 & 6,14 \\
Glutâmico & 10,97 & 5,39 & 5,32 & 5,96 \\
Histidina & 2,27 & 10,22 & 10,12 & 13,1 \\
Isoleucina & 5,1 & 2,23 & 2,56 & 2,26 \\
Leucina & 9,17 & 5,01 & 4,84 & 3,93 \\
Lisina & 6,28 & 8,89 & 8,85 & 10,1 \\
Metionina & 7,2 & 6,33 & 5,31 \\
Prolina & 2,07 & 1,65 & 1,71 & 0,57 \\
Serina & - & 4,64 & 5,4 & 5,75 \\
Tirosina & 4,47 & 5,16 & 4,6 & 6,43 \\
Treonina & 4,3 & 4,18 & 3,93 & 4,63 \\
Triptofano & 4,53 & 4,92 & 4,73 & 5,41 \\
Valina & 1,77 & 1,47 & 2,07 & - \\
\hline Eggun; & 5,8 & 5,73 & 5,58 & 5,41 \\
\hline Rogen & & &
\end{tabular}

${ }^{\mathrm{a}}$ Eggum; ${ }^{\mathrm{b}, \mathrm{c}}$ Rogers e Milner; ${ }^{\mathrm{d}}$ Tupynamba \& Veieira.

Fonte: Guerroué et al. (1996).

\section{Formas de utilização da parte aérea}

\section{Fresca}

A utilização direta da parte aérea fresca constitui a maneira mais simples e econômica de se fornecer aos animais, já que os custos diminuem consideravelmente, pois o processo se limita a fragmentação e a secagem da mesma. Segundo Machado et al. (2009) para variedades "mansas", basta picar e distribuir imediatamente nos cochos de alimentação. Se tratando de mandioca-brava, o autor recomenda fazer uma murcha, após a picagem do material, por um período mínimo de 24 horas. A forragem assim obtida deve ser misturada com $50,0 \%$ de outros volumosos (Carvalho, 1983) e a introdução na dieta deve ser gradativa.

Almeida \& Ferreira Filho (2005) recomendam que o fornecimento da folhagem fresca somente possa ser feito de 12 a 24 horas depois da colheita, para reduzir o princípio tóxico a níveis seguros, no caso de espécies com níveis um pouco mais altos de ácido cianídrico. Para espécies tidas como muito bravas, a rama deve ser misturada com outro tipo de volumoso, até a proporção máxima de $50 \%$ de rama.

Ramalho (2005) em um estudo sobre o fornecimento de rama de mandioca a bovinos concluiu que estes consomem cerca de $5 \mathrm{~kg}$ de matéria seca de parte aérea fresca, equivalente a 
$15 \mathrm{~kg}$ do material fresco. Esse consumo pode variar de acordo com o suplemento volumoso ou concentrado oferecido e com a categoria e idade dos animais trabalhados.

\section{Feno}

A fenação é um processo de conservação de forragens que, além de manter as qualidades do material após a colheita, facilita seu uso na fabricação de alimentos, eleva a concentração de nutrientes e elimina a maior parte do ácido cianídrico, reduzindo-o a níveis seguros para a alimentação animal (Kass et al., 1979).

O processo de produção do feno consiste, em linhas gerais, na trituração em pequenos pedaços de até 2,0 cm, usando-se uma picadeira de forragem para acelerar o processo e facilitar o armazenamento, conservação e uso no preparo de rações. Depois de triturado o material é exposto ao sol, em camadas uniformes, proporcionando uma densidade de até $15 \mathrm{~kg} / \mathrm{m}^{2}$, com objetivo de reduzir o teor de umidade de 65 a $80 \%$ existente nas ramas, para 10-14 \% no feno. Para acelerar a secagem, no primeiro dia, o material deve ser revolvido a cada duas horas, com um ancinho ou rodo de madeira.

Ao final da tarde, deve-se reunir o material e proteger com uma lona plástica, para evitar que durante a noite readquirira parte da umidade perdida durante o dia. O tempo de secagem depende das condições climáticas, umidade inicial das ramas, densidade, geometria dos pedaços e número de revolvimentos.

As condições para o armazenamento ou fornecimento aos animais deve ocorrer quando a umidade do material estiver entre 10 a $14 \%$. Uma maneira prática e eficiente para verificar a umidade é através da textura, onde se coloca uma porção do feno nas mãos e aperta-se. Caso o mesmo esteja quebradiço, pode ser considerado adequado com o teor de umidade abaixo de $14 \%$ (Carvalho, 1983).

A taxa de eficiência na produção de feno da rama está entre 20 e $30 \%$, onde $1000 \mathrm{~kg}$ de ramas produzem de 200 a $300 \mathrm{~kg}$ de feno, dependendo da época do corte, idade da planta, umidade inicial e relação caule-talo-folhas (Nascimento et al., 2005).

O armazenamento do feno pode ser feito em local com boa ventilação, alta temperatura, baixa umidade relativa e protegido da chuva. Para evitar fermentações indesejáveis e consequente deterioração do produto, o material armazenado não deve apresentar umidade superior a $14 \%$. Ressalta-se que a utilização do feno da rama na formulação de rações, pode reduzir a quantidade de cereais necessários para o balanceamento da ração, graças ao seu valor nutritivo (Lopes et al., 2005).

Nunes Irmão et al. (2008) estudaram a composição químico bromatológica do feno da rama da mandioca, preparado em diversas idades de colheita e concluíram que a rama não deve ser utilizada 16 meses após o plantio, principalmente para produção de feno voltada à alimentação de ruminantes, em função de uma menor qualidade nutricional que se reflete na redução da fração protéica, aumento da indisponibilidade do nitrogênio e aumento das cinzas insolúveis que não são utilizadas pelos ruminantes. Segundo o estudo, a melhor época de colheita da parte aérea para produção de feno é8 meses após o plantio, pois foi superior em relação à composição químico bromatológica, além de demandar um menor tempo de cultivo.

Alternativamente, o feno da parte aérea da mandioca pode ser triturado e transformado em farelo, o que facilita o manuseio, a conservação e a mistura com outros ingredientes da ração. Segundo Buitrago (1990), o farelo de parte aérea da mandioca com alta proporção de folhas deve apresentar 90,0\% de MS; 20,0\% de PB; 18,5\% de FB; $65,0 \%$ de NDT; $2,70 \mathrm{Mcal} / \mathrm{Kg}$ de energia digestível (ruminantes); $1,20 \%$ de Ca e $0,30 \%$ de P. De acordo com Wanapat et al. (1997), o feno da parte aérea da mandioca apresenta maior teor de PB e menores concentrações de FDN, FDA e lignina $(24,9 \%, 34,4 \%, 27,0 \%$ e $3,8 \%$, respectivamente) em relação ao feno de alfafa $(17,0 \%, 46,0 \%, 35,0 \%$ e $9,0 \%$, respectivamente).

$\mathrm{O}$ feno da parte aérea da mandioca apresenta maior concentração de nutrientes em relação à forragem fresca, podendo ser utilizado na preparação de suplementos protéicos para categorias de maior exigência nutricional, como vacas em lactação (GIL \& BUITRAGO, 2002). (Wanapat, 2002) sugeriu a suplementação com 1 a $2 \mathrm{~kg} / \mathrm{dia}$ de feno de parte aérea de mandioca para vacas em lactação, o que promove melhorias na produção e composição do leite, além de aumentar a vida de prateleira desse produto, devido à maior concentração de tiocianato (19,5ppm). Segundo a FAO (2003), o farelo da parte aérea da mandioca pode compor até $35 \%$ do concentrado para vacas leiteiras. Em um estudo comparativo do feno da parte aérea da mandioca 
com o feno da alfafa, concluiu ser a parte aérea da mandioca nutricionalmente superior, por apresentar menores teores de fibra e maiores teores de carboidratos, quando fornecido a novilhos (Carvalho \& Kato, 1987). Ainda se tratando de bovinos, Leonel (2001) relata ganho de peso de $1,3 \mathrm{~kg}$ de peso vivo por cabeça por dia em bovinos de corte semi-confinados utilizando rama de mandioca fresca triturada, com a oferta de $4 \mathrm{~kg}$ por cabeça por dia, e adição de protéico durante 60 dias, em fase terminal.

\section{Silagem}

A ensilagem, como técnica de conservação de forragens, tem sido largamente utilizada em propriedades rurais como estratégia de reserva forrageira para períodos críticos ou mesmo para uso contínuo na alimentação animal. Tem como objetivo eliminar o excesso de umidade (65 a 80 $\%$ ), aumentar a concentração de nutrientes, reduzirem o teor de ácido cianídrico a níveis seguros com mínimas perdas de matéria seca e energia durante a sua preservação, além de facilitar a incorporação do produto final em rações balanceadas (Machado et al., 2009).

Silagem é definida como o alimento volumoso obtido por estocagem direta ou com secagem mínima da forragem em condições anaeróbicas no silo, cuja preservação é garantida por ambiente anaeróbico e fermentação bacteriana de açúcares, os quais propiciam queda do $\mathrm{pH}$ através da produção de ácido lático e acético(Souza \& Fialho, 2003). Estes mesmos autores relatam que para uma boa silagem, as plantas devem atender as seguintes premissas: quantidades adequadas de substratos fermentescíveis (6-8\% de CHO solúvel na MS), poder tampão relativamente reduzido e porcentagem de MS acima de 30\%. Tais características contribuem para obtenção de padrões desejáveis de fermentação.

A técnica de emurchecimento é uma importante ferramenta a ser utilizada principalmente por elevar o teor de matéria seca, concentração de carboidratos solúveis e reduzir o poder tampão, melhorando as condições para atuação das bactérias láticas. $\mathrm{O}$ processo consiste na redução da atividade de água da forragem ou elevação da pressão osmótica intracelular, em forragens com elevados teores de umidade.

A tecnologia de ensilagem da parte aérea da mandioca deve seguir o mesmo princípio para conservação de qualquer forrageira. Devem-se tomar todos os cuidados em relação ao carregamento, compactação, vedação e posterior descarregamento do silo.

Arama deve ser picada e devidamente compactada. Embora a ensilagem da parte aérea da mandioca sem picar também seja viável, desde que se use trator pesado para obter alta densidade. É preferível sempre picar o material em partículas de 1 a $2,5 \mathrm{~cm}$ (porém deve-se atentar a partículas muito pequenas, estas fazem com que o material perca a característica de volumoso), pois esse procedimento possibilita uma melhor compactação com aumento da densidade, e consequente redução dos bolsões de ar entre o material. Assim, haverá melhor qualidade de fermentação e maior estabilidade da silagem durante a utilização (Souza \& Fialho, 2003). Estes mesmos autores afirmam que, uma boa compactação deve proporcionar em torno de $600 \mathrm{~kg} / \mathrm{m}^{3}$ de silagem. Normalmente, silos tipo trincheira revestidos proporcionam melhores condições de compactação e perdas insignificantes, embora a silagem também possa ser feita em outros tipos de silos, desde que adequadamente manejados.

Oliveira et al. (1984) trabalhando com feno e silagem de rama de mandioca (parte aérea total e do terço superior) para carneiros, não encontraram diferenças significativas de valor nutritivo $(\mathrm{VN})$ e balanço de nitrogênio $(\mathrm{BN})$ no feno e na silagem. Embora sem diferenças significativas, observaram que, numericamente, o $\mathrm{VN}$ e BN foram superiores para o feno e a silagem do terço superior da rama.

Azevedo et al. (2006) caracterizando a parte aérea de cinco cultivares de mandioca quanto à qualidade nutricional com vistas à alimentação de ruminantes, encontraram teores de $\mathrm{PB}$ variando entre 7,2 a $10,4 \%$. Valores superiores foram relatados por Faustino et al. (2008) e Modesto et al. (2004), respectivamente 20,58 e 19,5\% PB. As variações no conteúdo de proteína das silagens de rama estão relacionadas à idade de maturação, variedade e porção da planta utilizada, pois quanto mais jovens forem as folhas e quanto maior for o seu percentual na parte aérea obtêm-se um volumoso mais protéico.

\section{Considerações finais}

A parte aérea da mandioca pode ser uma alternativa para redução dos custos de produção na atividade pecuária, visto que é um subproduto pouco aproveitado pelos produtores rurais. A sua utilização como feno e/ou silagem, 
principalmente quando confeccionados com o terço superior da planta, são excelentes volumosos para a alimentação de ruminantes. Já a forma in natura necessita passar por um processo de murcha, para volatilização parcial do HCN até que este atinja níveis seguros para seu fornecimento aos animais. Deve ser ressaltado que, estudos relacionados à sua utilização como fonte de proteína vegetal na nutrição de ruminantes são escassos havendo a necessidade de mais pesquisas e difusão entre os produtores rurais.

\section{Referências Bibliográficas}

Aletor, O. 2010. Comparative, nutritive and physico-chemical evaluation of cassava (Manihot esculenta) leaf protein concentrate and fish meal. Journal of Food, Agriculture and Environment, 8, 39-43.

Almeida, J. \& Ferreira Filho, J. R. 2005. Mandioca: uma boa alternativa para alimentação animal. Bahia Agrícola, 7, 51-55.

Alves, E., Vedovoto, G., Gameiro, A., Cardoso, C., Camargo, B., Antiqueira, T. \& Guimarães, V. 2003. A indústria do amido de mandioca. Embrapa Informação Tecnológica.

Azevedo, E. B. d., Nõrnberg, J. L., Kessler, J. D., Brüning, G., David, D. B. d., Falkenberg, J. R. \& Chielle, Z. G. 2006. Silagem da parte aérea de cultivares de mandioca. Ciência Rural, 36, 1902-1908.

Bohnenberger, L., Gomes, S. D., Coelho, S. R. M. \& Boscolo, W. R. 2010. Concentrado protéico de folhas de mandioca na alimentação de tilápias do nilo na fase de reversão sexual. Revista Brasileira de Zootecnia, 39, 1169-1174.

Buitrago, J. A. 1990. La yuca en la alimentación animal. CIAT, Colombia.

Carvalho, J. L. H. 1983. A mandioca, raiz e parte aérea na alimentação animal. EMBRAPA.

Carvalho, V. \& Kato, M. 1987. Potencial de utilização da parte aérea da mandioca. Informe Agropecuário, 13, 23-28.

Conceição, A. J. 1987. A mandioca.

Fasuyi, A. O. \& Aletor, V. A. 2005. Varietal composition and functional properties of cassava (Manihot esculenta, Crantz) leaf meal and leaf protein concentrates. Pakistan Journal of Nutrition, 4, 43-49.
Faustino, J. O., Santos, G. T., Modesto, E. C., Silva, D. C., Jobim, C. C., Sakaguti, E. S., Damasceno, J. C., Araújo Marques, J. \& Zambom, M. A. 2008. Efeito da ensilagem do terço superior da rama de mandioca triturada ou inteira e dos tempos de armazenamento. Acta Scientiarum. Animal Sciences, 25, 403410.

Ferreira, G. D. G., Oliveira, R. L., Cardoso, E. d. C., Magalhães, A. L. R. \& Brito, E. L. 2008. Valor nutritivo de co-produtos da mandioca. Revista Brasileira de Saúde e Produção Animal, 8, 364-374.

Gómez, G. \& Valdivieso, M. 1985. Cassava foliage: chemical composition, cyanide content and effect of drying on cyanide elimination. Journal of the Science of Food and Agriculture, 36, 433-441.

Guerroué, L., Douillard, R., Cereda, M. P. \& Chiarello, M. D. 1996. As proteínas de folhas de mandioca: aspectos fisiológicos, nutricionais e importância tecnológica. Boletim do Centro de Pesquisa e Processamento de Alimentos, 14, 133-50.

Harborne, J. B. 1999. An overview of antinutritional factors in higher plants. In: Caygill, J. C. \& Mueller, H. (eds.) Secondary plants products. Antinutritional and beneficial actions in animal feeding. Nottingham Univ Press, UK.

IBGE. 2013. Contas nacionais trimestrais. Jul.set. 2013. 20th ed. Available in: www.ibge.gov.br, Rio de Janeiro, BR.

Kass, M., Albuquerque, M. \& Ramos, C. 1979. Concentração e métodos de eliminação de ácido cianídrico em folhas de mandioca (Manihot esculenta Crantz). Centro de Pesquisa Agropecuaria do Tropico Umido, Belem-Para, Brasil.

Leonel, M. 2001. Uso dos subprodutos da industrialização da mandioca na alimentação animal. In: Cargill, F. (ed.) Fundação Cargill.

Lopes, F.C.F.; Arcuri, P.B.; Carneiro, J.C. Mandioca na alimentação de bovinos. In: SOUZA, L.S., FARIAS, A.R.N., MATTOS, P.L.P. (Ed.). Processamento e utilização da mandioca. Cruz das Almas: EMBRAPA Mandioca e Fruticultura Tropical, 2005, p.444-515.

Machado, F. S., Gonçalves, L. C., Faria Júnior, W. G. \& Ribas, M. N. 2009. Coprodutos da 
mandioca na alimentação de gado de leite. In: Gonçalvez, L. C., Borges, I. \& Ferreira, A., P. D. S. (eds.) Alimentos para gado de leite. FEPMVZ, Belo Horizonte.

Modesti, C. F., Corrêa, A. D., Oliveira, E. D., Abreu, C. M. P. \& Santos, C. D. 2007. Caracterização de concentrado protéico de folhas de mandioca obtido por precipitação com calor e ácido. Ciência e Tecnologia de Alimentos, 27, 464-469.

Modesto, E. C., Santos, G., Vilela, D., Silva, D., Faustino, J., Jobim, C., Detmann, E., Zambom, M. \& Marues, J. 2004. Caracterização químico-bromatológica da silagem do terço superior da rama de mandioca. Acta Scientiarum. Animal Sciences, 26, 137-146.

Modesto, E. C., Santos, G. T., Vilela, D., Silva, D. C., Faustino, J. O., Detmann, E., Zambom, M. A. \& Araújo Marques, J. 2008. Caracterização químico-bromatológica da silagem do terço superior da rama de mandioca. Acta Scientiarum. Animal Sciences, 26, 137-146.

Moreira, F. B., Prado, I. N., Cecato, U., Wada, F. Y. \& Mizubuti, I. Y. 2004. Forage evaluation, chemical composition, and in vitro digestibility of continuously grazed star grass. Animal Feed Science and Technology, 113, 239-249.

Nascimento, G., Costa, F. G. P., Amarante Junior, V. \& Barros, L. R. 2005. Efeitos da substituição do milho pela raspa de mandioca na alimentação de frangos de corte, durante as fases de engorda e final. Ciência $e$ Agrotecnologia, 29, 200-207.
Ramalho, R. P. 2005. Raspa de mandioca na alimentação de vacas leiteiras. Revista Científica de Produção Animal, 7.

Ravindran, V. 1992. Preparation of cassava leaf products and their use as animal feeds. FAO Animal Production and Health Paper, 95, 111-125.

Silva, A., Santana, L., França, C., Magalhães, C., Araíjo, C. \& Azevedo, S. 2009. Produção de diferentes variedades de mandioca em sistema agroecológico. Revista Brasileira de Engenharia Agrícola e Ambiental, 13, 33-38.

Souza, L. S. \& Fialho, J. F. 2003. Cultivo da mandioca para a região do Cerrado. Embrapa Mandioca e Fruticultura, 8.

Wanapat, M. 2002. The role of cassava hay as animal feed. 7th Regional Workshop. Bangkok.

Wanapat, M., Pimpa, O., Petlum, A. \& Boontao, U. 1997. Cassava hay: A new strategic feed for ruminants during the dry season. Livestock Research for Rural Development, 9, 1-5.

Recebido em Agosto 72014

Aceito em Novembro 4, 2014

License information: This is an open-access article distributed under the terms of the Creative Commons Attribution License, which permits unrestricted use, distribution, and reproduction in any medium, provided the original work is properly cited. 